\title{
المدلول الرمزي للعروسة الثعبية عند عينة مختارة من الفنانين المصريين المعاصرين لإثراء المشغولة الفنية
}

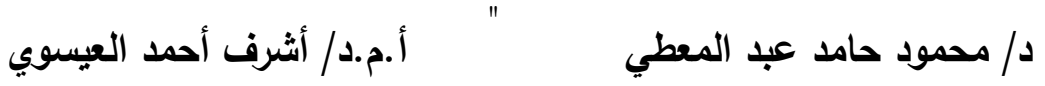

سميرة كامل على أبو ناشي

ماجستير تربية فنية

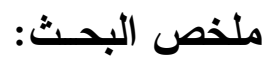

يهدف البحث الي دراسة المدلول الرمزى للعروسة الثعبية والوعى بدلالاتها وابعادها التاريخية والفلسفية في اعمال العينة المختارة من الفنانين المصريين المعاصرين لإمكانية الانطلاقة منها إلى ممارسات فنية تجريبية ، واستلاهام هذه الدلالات المتعددة فى إنتاج اعمالاً فنية معاصرة ، قد تثرى مجال الاشغال الفنية

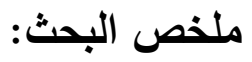

The research aims to Study symbolic significance of popular bride and awareness Bdalaladtha historical, philosophical and dimensions in the selected sample of the works of contemporary Egyptian artists to launch them to the possibility of experimental art practices, and inspired by these multiple connotations in the production of contemporary works of art, you may enrich the field of technical works. 


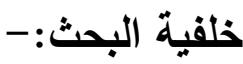

بُعد الفن الثعبى لغة لها مقوماتها ووجودها فهوأحد مصادر التراث التى لا تزال تعيش

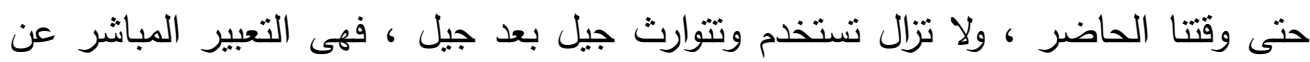

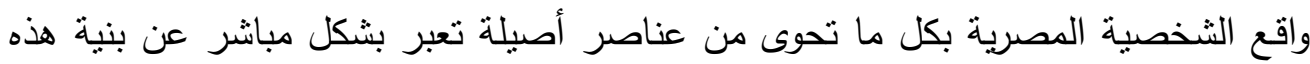

$$
\text { الثخصية فى صدقها وواقعية قيمتها الابداعية. }
$$

وبما أن الفنون الثعبية كانت ولا تزال أحد الأنماط التى أثرت الإنسانبة بخصائصها والثها

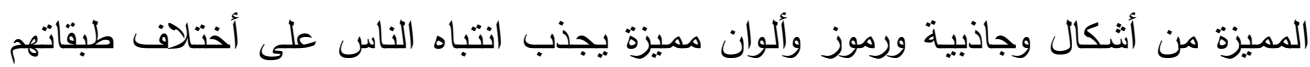

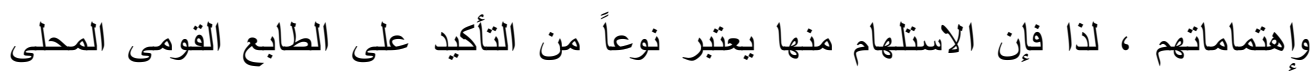
لتحقيق مفهوم الإنتماء) فهذا الفن يعد فناً متميزاً يحمل خلاصات القيم الثقافية والأجتماعية غير بعيداً عن الأنماء المجتع الذى يعيش بداخلة الفنان مراعباً الخامات المتاحة فى البيئة والوحدات الزخرفية

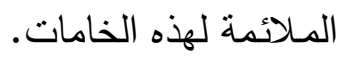

لذللك فإن تراث الفن الثعبى يعد مادة خصبة للاستلاهام منه فى سبيل بعث فن قومى له مظاهرة الخاصة ، لذلك نجد أن كثير من الثعوب قد اتخذت لها شعارات أو نماذج فنية

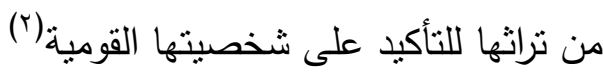
لذا فإن التاريخ الإنسانى عبر الحضارات يحوى كثيراً من الرموز ذات الداتهات الداتلات

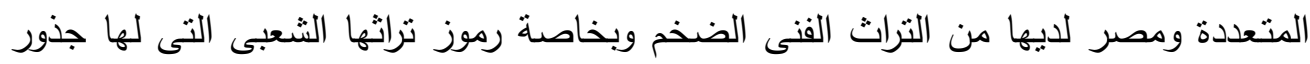

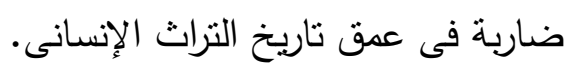
لذلك ترجع الرموز الثعبية إلى أصول عقائدية لها وجودها الدائم خلال تغير وتحول

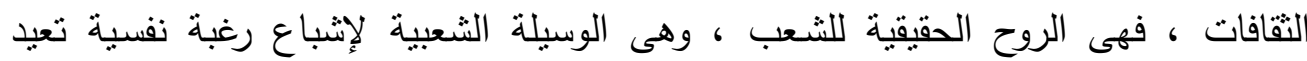
الإنسان إلى حالته الإتزانية ، كإحساس داخلى بإمتصاص ما كان يشغله.

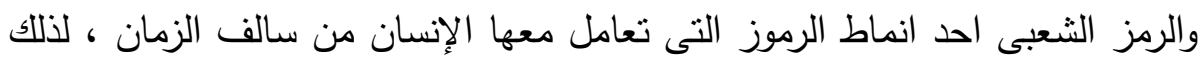

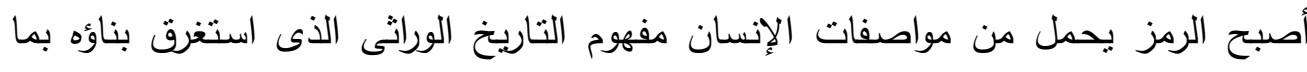

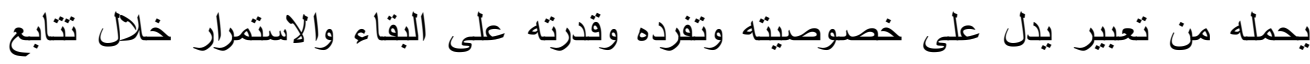

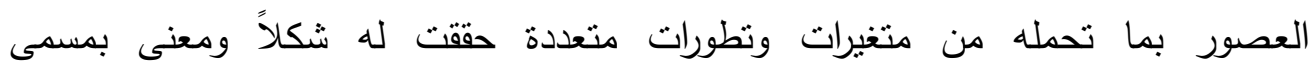

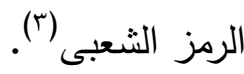


لذلك كان لرمز للعروسة الثعبية الدور الخاص حيث تتوعت تشكيلاتها من الثكل الورقي المشهور إلي عروسة المولد إلي العروسة الثعبية وبينهما مشوار طويل بدأ من لن العصر الفرعوني ولم ينتهي إلي هذا اليوم والعروسة اختلفت في أنثالها باختلاف العصور واختلفت في مهنها حسب التراث الثعبي.

لذلك تحاول الدارسة أن تلقى الضوء على الأعمال الفنية لعينة من الفنانين

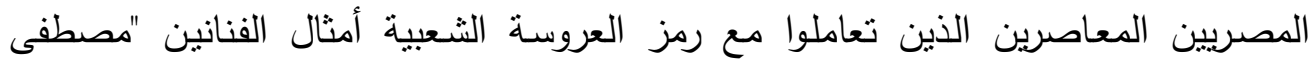
الرزاز - على المليجى - فرغلى عبد الحفيظ - عصمت داوستاشى " ، الذين تتاولوا العروسة الثعبية بمدلول بصرى ورمزى تعبيراً عن افكار ومعتقدات وميول خاصة أثرت

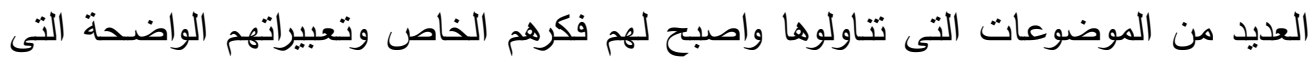

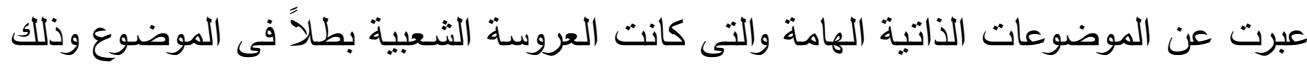
للوقوف على اهم القيم الفنبة المختلفة التى تجسدت فى أعمالهم الفنية وعبرت عن شكل العروسة

الثعبية بتقنياتهم المختلفة وتعبيراتهم الفريدة حتى يتسنى لنا الاستلهام من اعمالهم الفنية

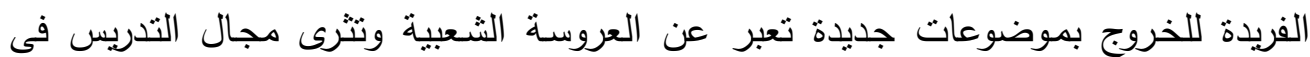

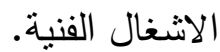
|- ا-لفنان مصطفى الرزاز :-

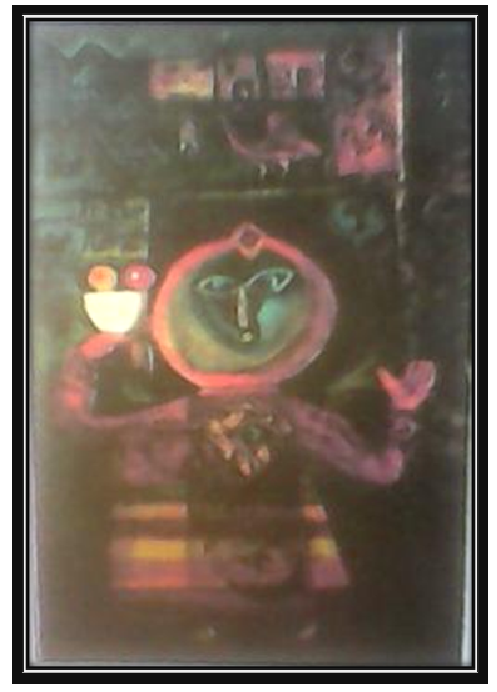

مصطفى الرزاز ،العروسة الثعبية ، متحف الفن الحديث،؛ـ97 ـ. 
فى هذا العمل استخدم الفنان العروسة الثعبية حيث تتصدر اللوحة ، فصاغها بشكل

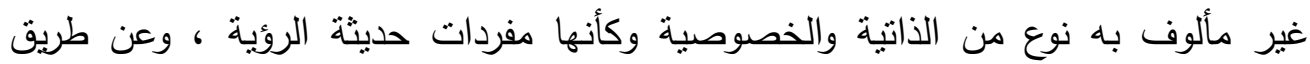
التكوين المترابط نرى التوزيع المتزن لمفردات العمل فى جميع المحاور الإنشائية التى نوحى لتى بحس فنى عالى ، كما يظهر خلف العروسة على الجدار ايقونات وموتيفات للفن الثعبى المصرى ، واللوحة مستطيلة الثكل تظهر العروسة واضحة بحجمها وتفاصيلها ، حيث ترى مقدمة العمل وخلفيته ويمينه ويساره بشكل به نوع من الأتزان والاتجاه العام شعبى ذو نزعة

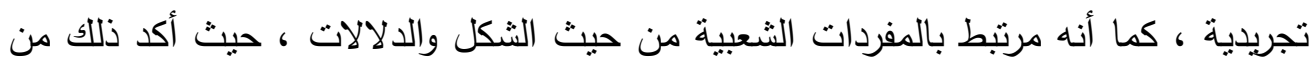
خلال نمط تعبيرى بصرى. r-الفنان على المليجى:-

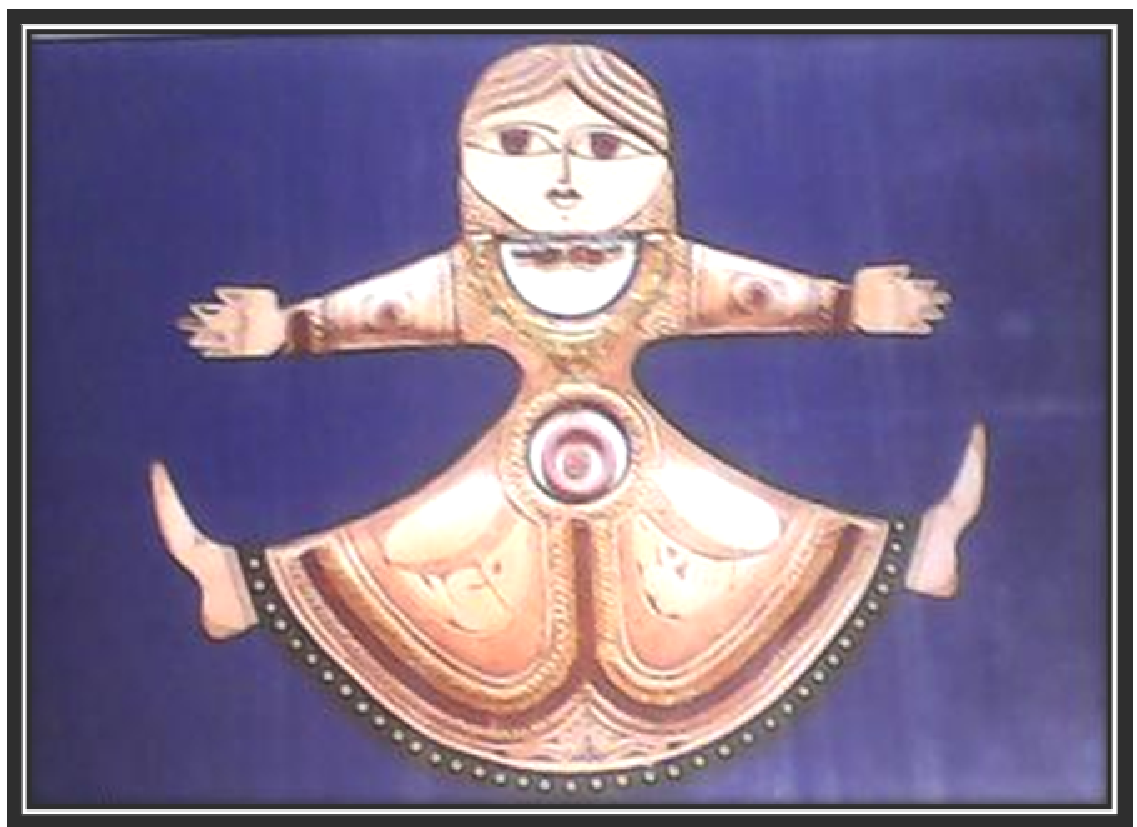

على المليجى ، وجهاك مشرق "معلقة" ، مجلة الدوحة ، 1914.

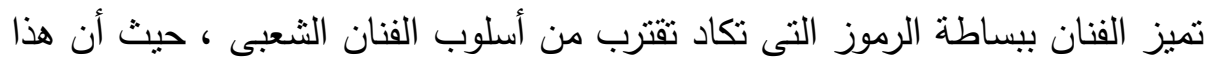
العمل هو عروسة من الجلد الحور ، الرأس مستديرة وملامح الوجة شعبية ويحيط بالوجة

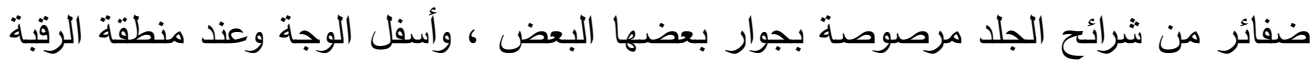

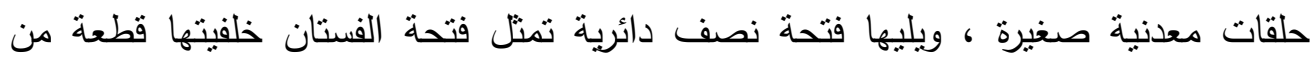

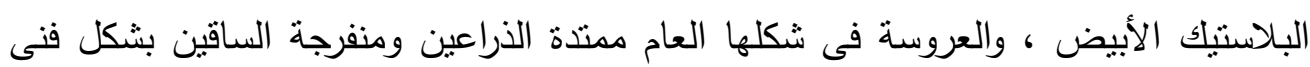


رشيق متكامل من الناحية التشكيلية ، والكفين مرسومتين بالحرق ويأخذ شكلاً زخرفياً جميلاً ،

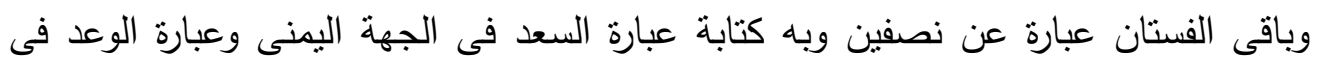
الجهة اليسرى، وفى النهاية يوجد القدمين حيث يسويان إلتقاء فنى تشكيلى مع الأيدى الممتدين إلى الجانبين. r-القنان فرغلى عبد الحفيظ:-

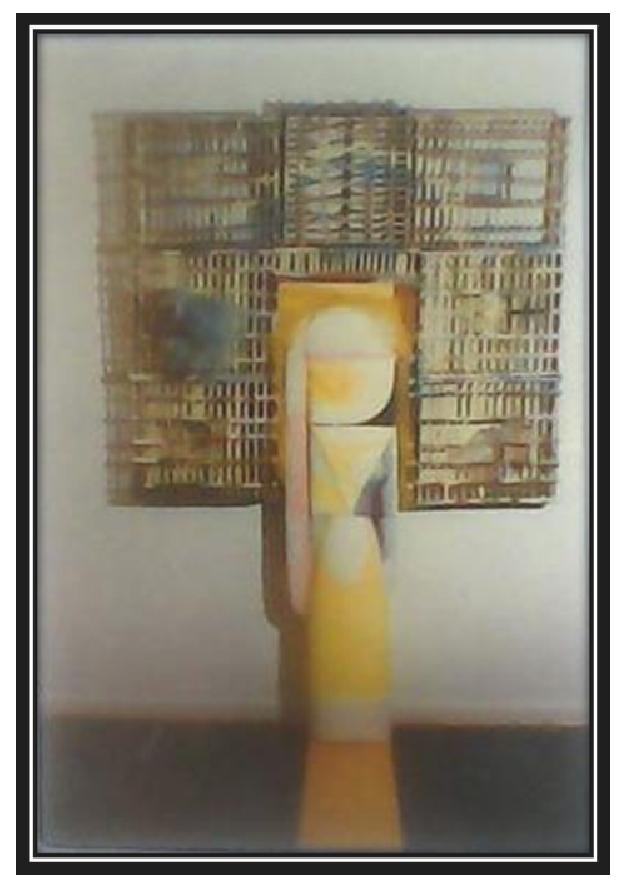

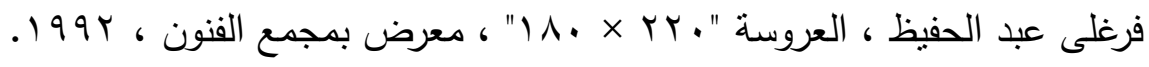
ترى فى اعمال الفنان ملامح البيئة المصرية التى ارتبط بها والتى شكلت الأنطلاقة الأولى لتجاربة الفنية وحددت رؤيته التتكيلية ، حيث ان رمز العروسة هو رمز خاص باصليه بالفنان ملازم له فى اعماله حيث يعبر فى هذا العمل عن التلاحم بين الفن والطبيعة ليتعانق

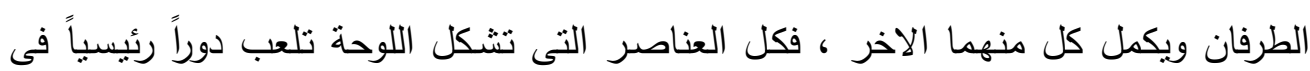
خدمة الجوانب الرمزية والبنائية فبينما ترمز العروسة إلى العنصر البشرى يتحقق المستوى

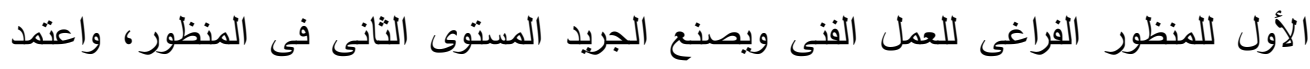
الفنان فى هذه اللوحة مباشرة مع الحيز والمسافات والفراغات ، وايضا استخدم خامة الجريد وهى من الخامات المنتشرة فى الريف والنوبة. 
צ-القنان عصمت داوستاشى:-

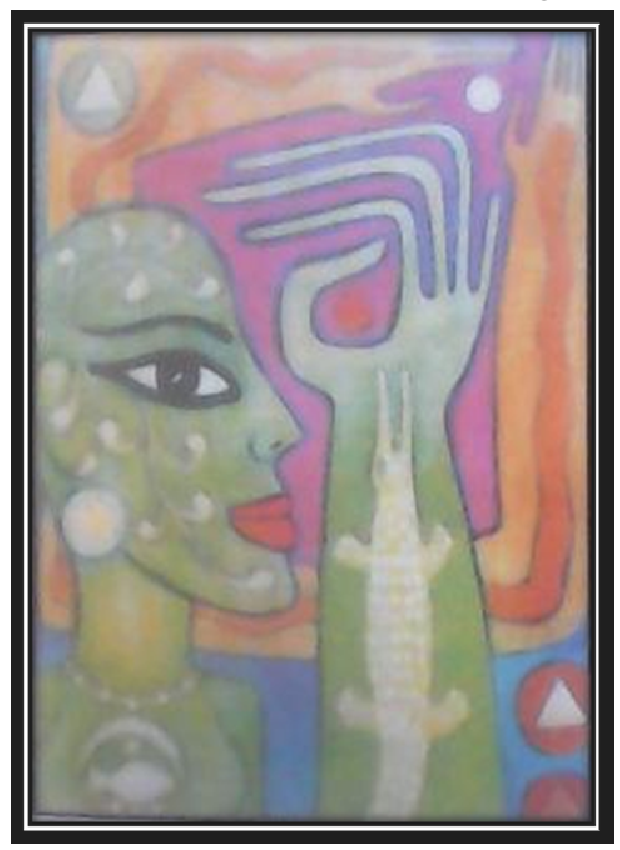

عصدت داوستاشى ، التعويذة " 9 × . . 1" ، متحف الفن الحديث ، . . . .

اعتمد الفنان فى الصياغة على الثكل الهرمى وذللك لإظهار المحتوى الرمزى لمفردات

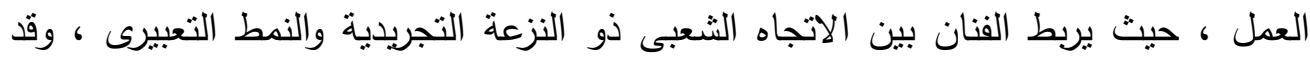

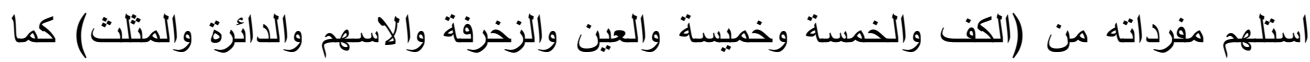

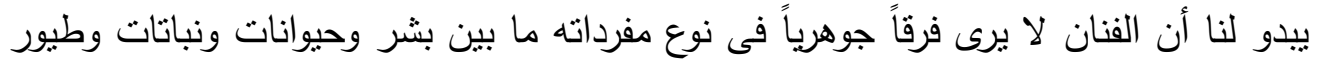
، فلا يعيد ترتيبها داخل العمل وإنما يعيد صياغاتها صياغة جديدة. ومن هنا اهتمت الدارسة بربط الصلة بين الفن التشكيلى والتراث فى الكثير من

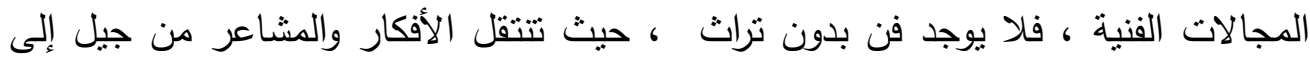

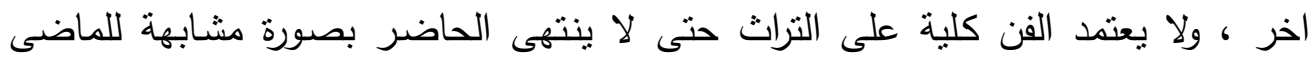
فينمحى فيه الإبتكار وتضمحل الإضافة الجديدة. فيعد مجال الاشغال الفنية من أهم المجالات الفنية التى تهنت بدراسة التراث ، والذهى

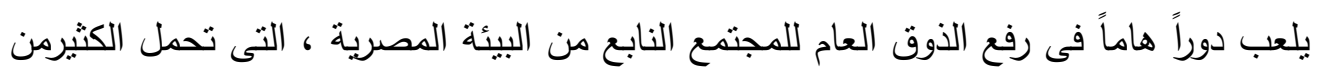

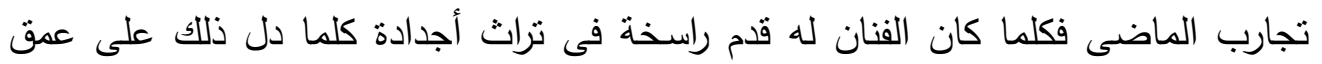
نظرته فيخرج من خلالها بمشغولات فنية تحمل قيم جمالية ووظيفية تتميز بالأصالة والمعاصرة. 
لاحظت الدارسة أن نتاول المدلول الرمزى للعروسة الثعبية بشكل خاص يُعد رمزاً

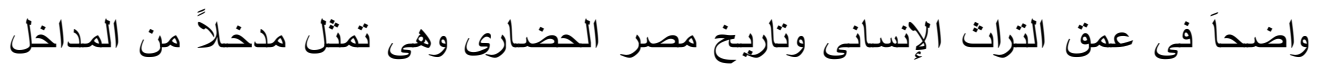

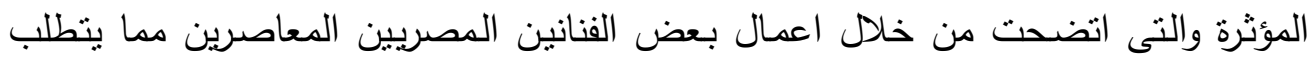

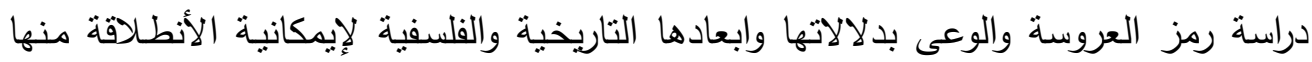

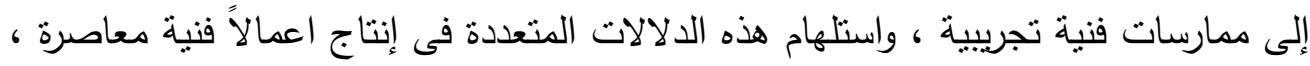
قد تثرى مجال الاشغال الفنية.

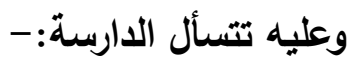

1- كيف يمكن الحصول على صياغات تشكيلية جديدة فى مجال الاشغال الفنية من العروسة

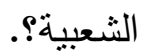
r- كيف يصبح المدلول الرمزى للعروسة الثـعبية عند عينة مختارة من الفنانين المصريين

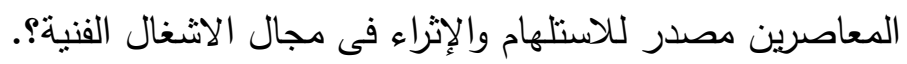

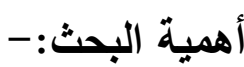
1-التأكيد على تعميق الثعور بالإنتماء للتراث الشعبى.

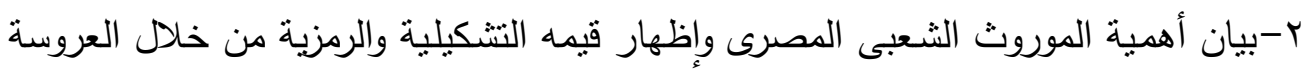
الشعبية. r-تتاول المدلول الرمزى للعروسة الثعبية بالدراسة والتحليل وإعادة تقديمها يؤدى إلى إضافة

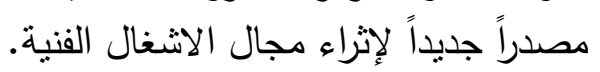

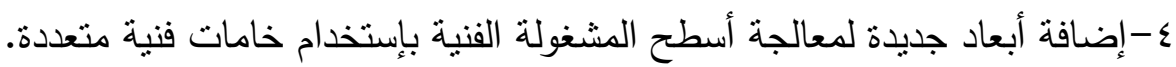

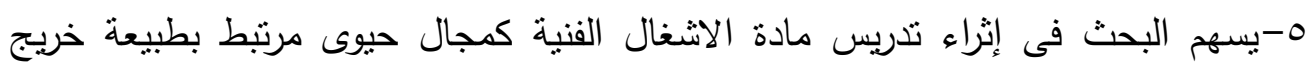
الكلية . 7-يسهم البحث فى التأكيد على أهمية الأعمال الفنية السابقة للعروسة التى تحتوى على مضمون فلسفى للقيم الرمزية لخلق تكوينات جديدة ذات مضمون تعبيرى جيد.

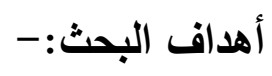

1-إلقاء الضوء على العروسة الثعبية من حيث بداية ظهورها وتطورها التاريخى واهميتها

$$
\text { فى تاريخ فنوننا الثعبية. }
$$

r-الوصول إلى رؤى فنية معاصرة للعروسة الثعبية المصرية لصئة الصياغة مشغولات فنية.

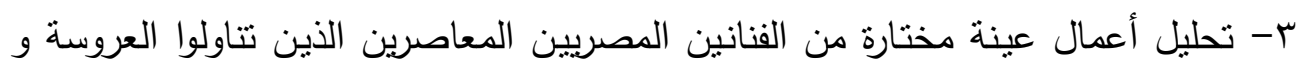

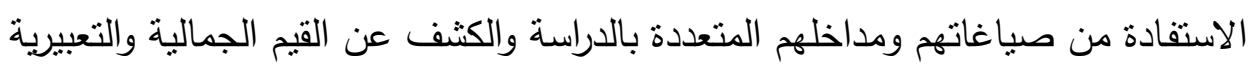
ومنطلقات الاستلاهام من اعمالهم. ع-إيجاد مداخل جديدة لتدريس الاشغال الفنية بما يتلائم مع العصر وذللك بإستخدام العروسة الثعبية. 
1-ثقتصر الدراسة على الاستلهام من أثنكال العرائس الثعبية فى اعمال عينة مختارة

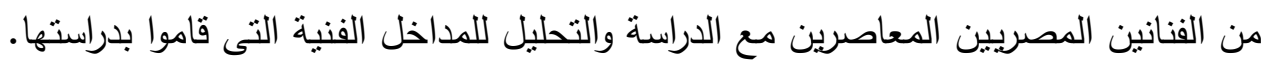

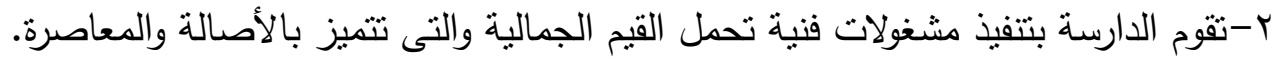
r-الجمع بين التقنيات الفنية المختلفة التى تتشأ عن استخدام الخامات الفنية على لقلى أسطح المشغولات الفنية.

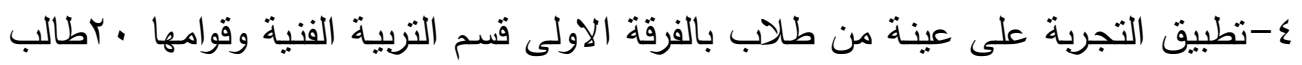
وطالبة فى مادة الاشغال الفنية بكلية التربية النوعية - جامعة الفئة المنوفية.

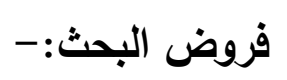

ا-تفترض الدارسة أنه من خلال دراسة المدلول الرمزى للعروسة الثعبية عند عينة مختارة

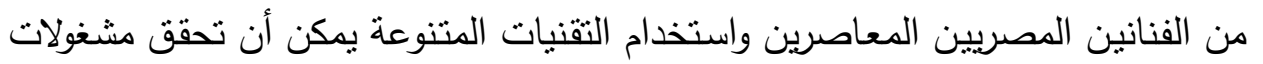

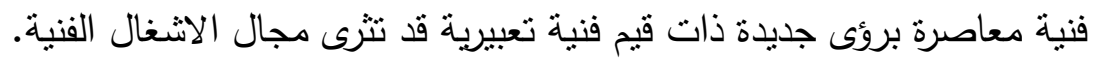

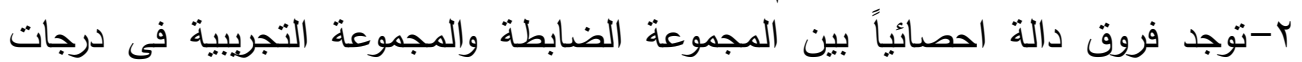
الاشغال الفنية تكون هذه الفروق لصالح المجموعة التجريبية.

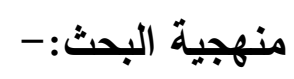

تعتمد الدراسة على المنهج الوصفى التحليلى للإطارالنظرى والمنهج التجريبى للإطار

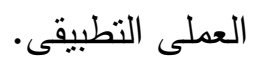

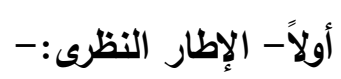

ا-دراسة تاريخية لرمز العروسة بأبعادها وتطورها ودلالاتها الفلسفية والتعبيرية عبر التراث

$$
\text { الإنسانى والتراث المصرى. }
$$

ץ-تحليل ودراسة عينة مختارة من اعمال الفنانين المصريين المعاصرين الذين الفين تتاولوا رمز

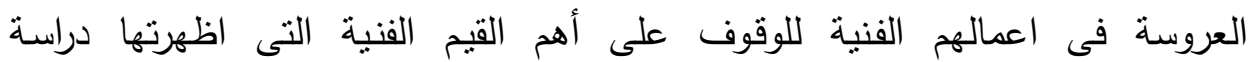
العروسة الثعبية.

$$
\text { ثانياً - الإطار التطبيقى:- التروسة }
$$

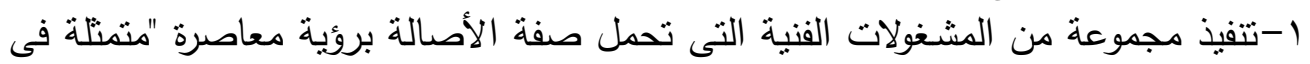

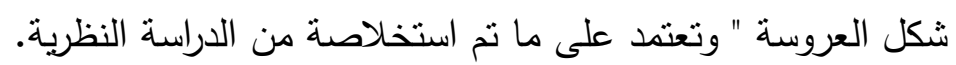

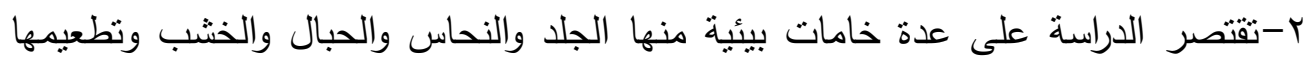

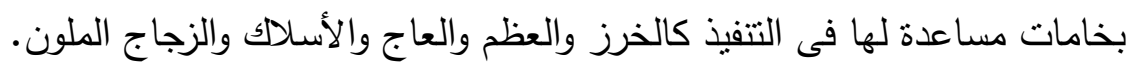
ז-عرض لتطبيقات الطلاب على لجنة من المحكمين.

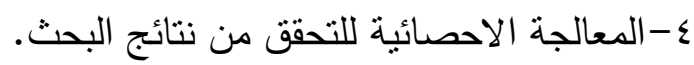

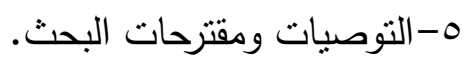




\section{مصطلحات البحث: - -}

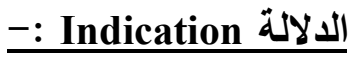

يشتق من الدلالة الفعل (دل) على الثئ (ودلالة) بمعنى أرشد فهو دال والثئ مدلول

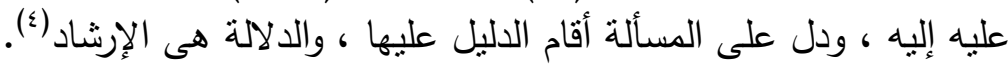

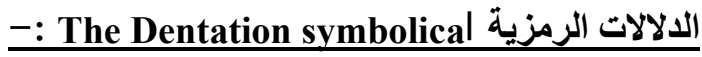

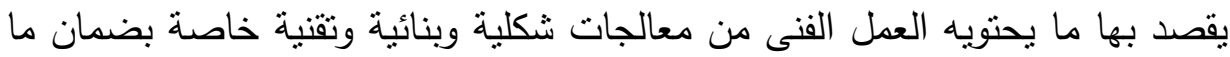

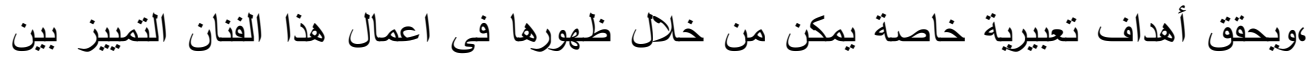

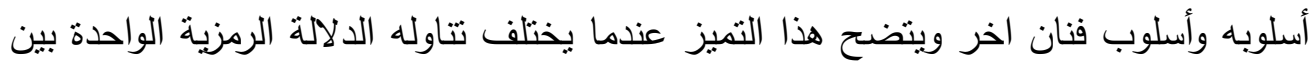

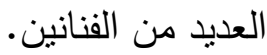

\section{-:The Dentation الدلالاتن}

هى المعانى النى تحتاج إلى عملية فكرية أكثر تعقيداً من الإدراك الحسى والأنطباعات

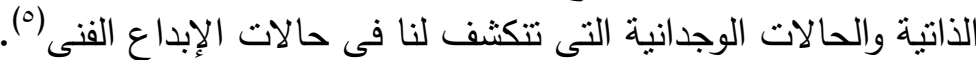
وهناك دلالات سماوية مثل المعتقدات ودلالات أرضية مثل الظواهر الطبية الطبية الطية ودلالات

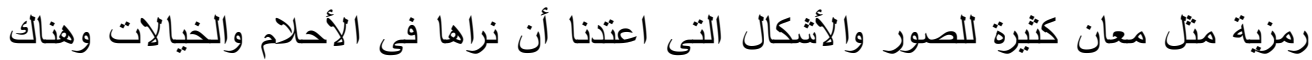

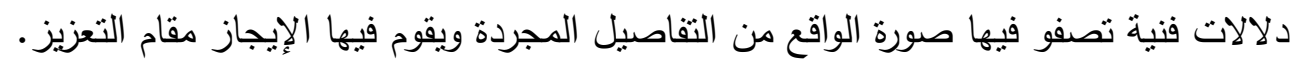
الرمز Symbol

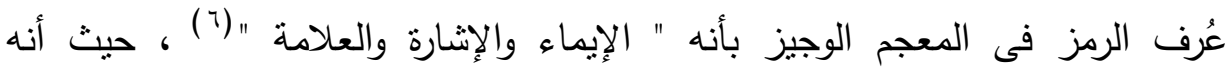

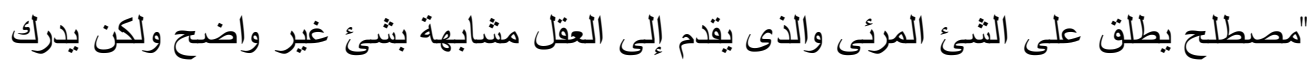

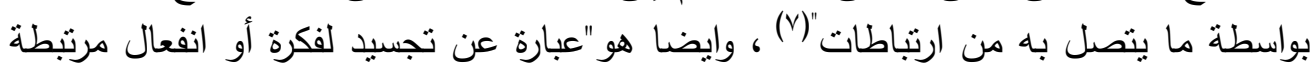

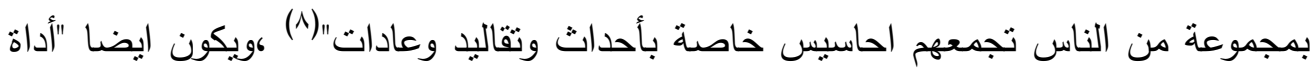

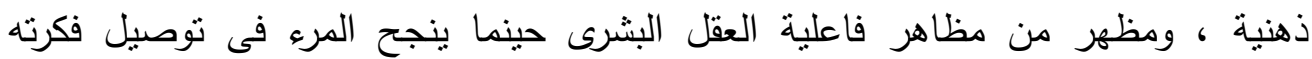

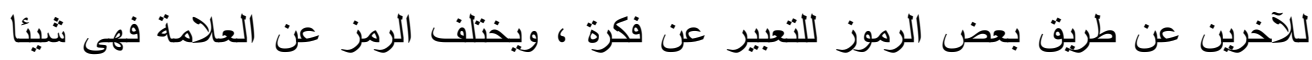

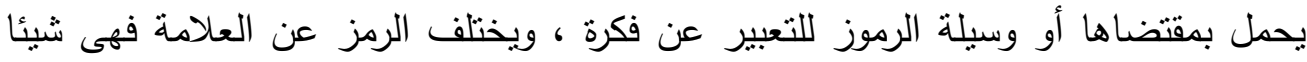

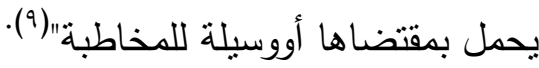
الرمز في الفنون الثعبية:-

يقصد به الوحدة الفنية التى يختارها الفنان الثعبى من بيئته كى يحمل بها إنتاجه الفنى ويكسبه طابعاً فريداً فى نوعه على أن يكون محملاً بالقيم النقافية والاجتماعية لبيئته ومعبراً

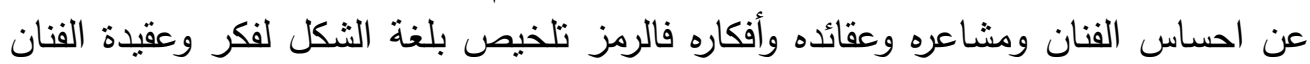
وتعبيراً عن احساسه نحو بيئته. العروسة The Doll

اشتق اسم العروسة Pupet نلاك الكلمة الانجليزية من أصل إيطالى من كلمة بمعنى Popa

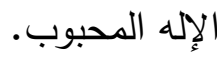


كما ترجع كلمة عروسة Pupus - Pupo اللاتينى بمعنى طفل صغير مولود ، ولقد

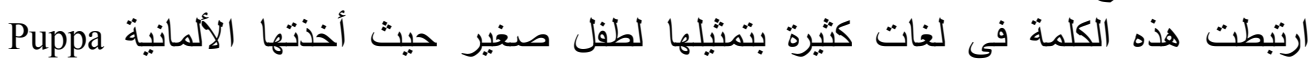

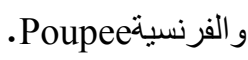

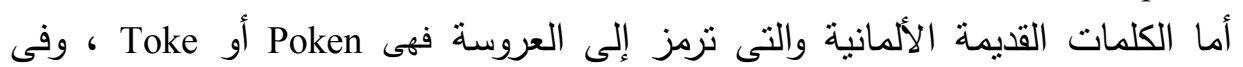

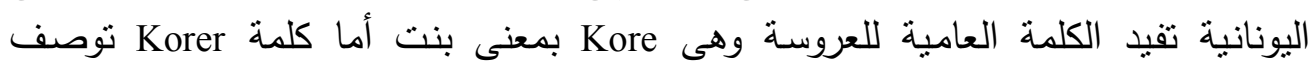

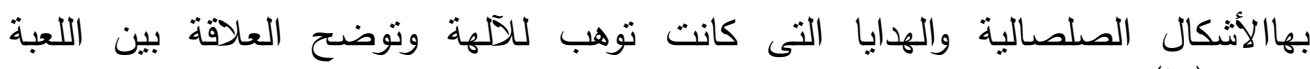
والقربان (·) (')

إلا أن مجمع اللغة العربية أدخل لفظ عروسة بمعنى دمية ضمن الكلمات التى شاع

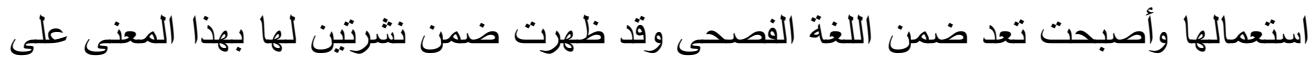

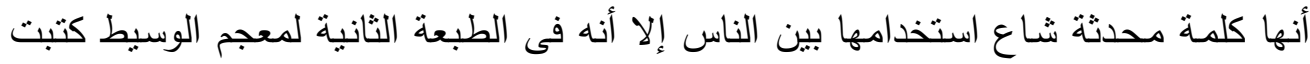

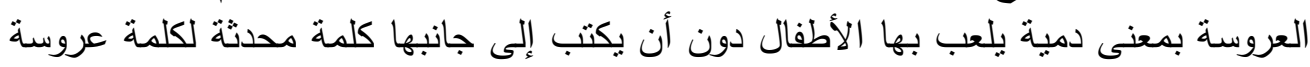
كما يوجد ألفاظ عربية أخرى مرادفة لها تختلف بإختلاف الموقع فقى العراق تسمى اللعاب (الدمى). الموسوعة الأمريكية The Encyclopedia Americana

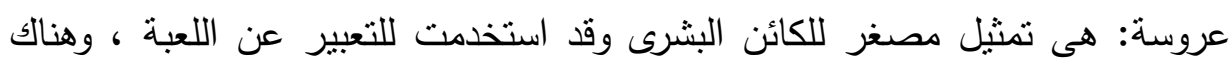

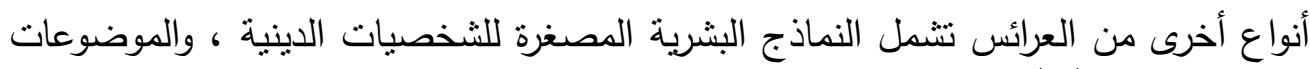

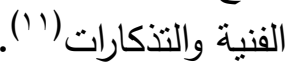

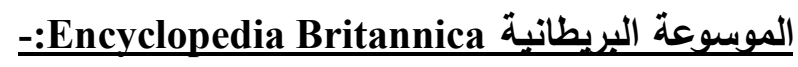
لعبة للطفل ممثلة فى شكل إنسان أو حيوان ، هئ أقدام اللعب فوجدت العرائس مصاحبة

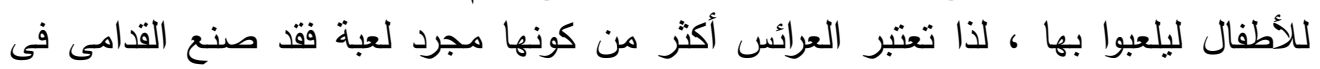

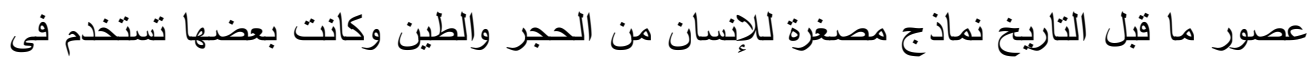

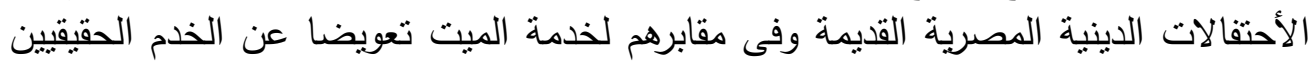

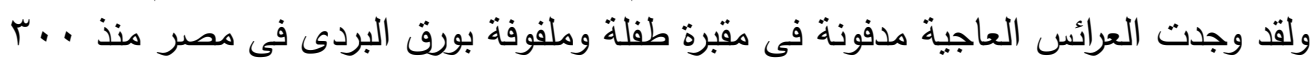

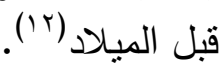

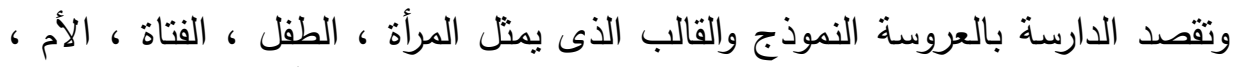

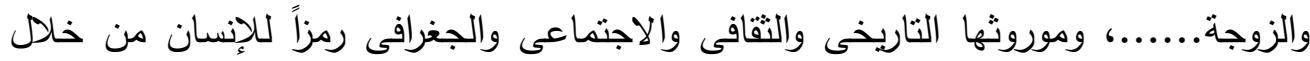

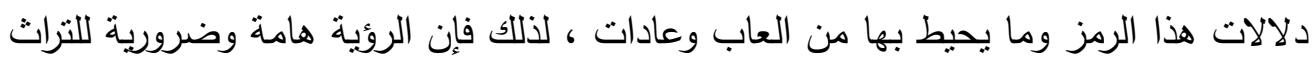

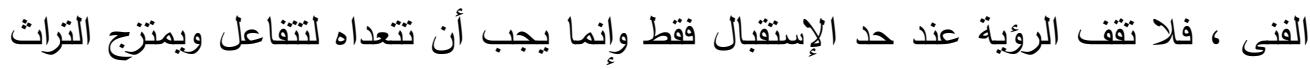
بالمعاصرة لينتشر ويستمر بين الناس.

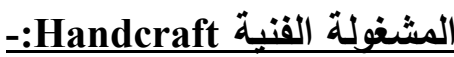

هى عملية المنتج أو الابتكار الذاتى لتغيرات جمالية قوامها استغلال الخامات الطبيعية

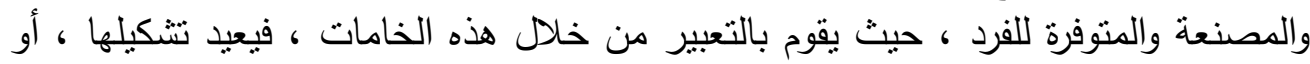

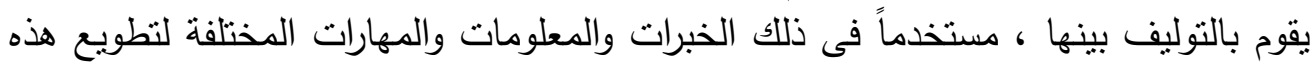

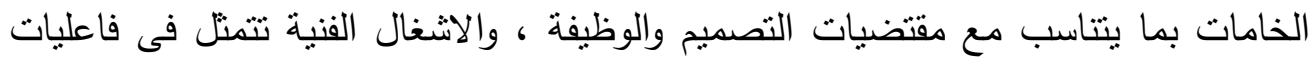


متعددة منها "الأشكال المجسمة ذات الثلاث أبعاد أو المسطحة ذات البعدين واحياناً تأخذ

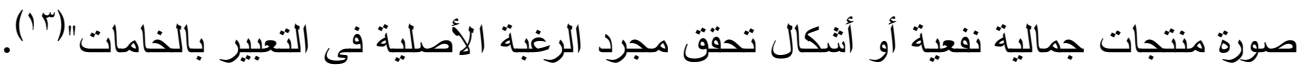

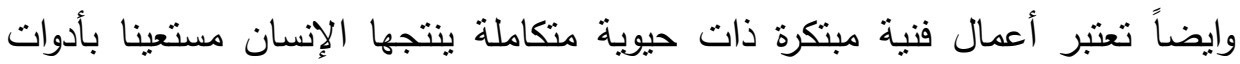

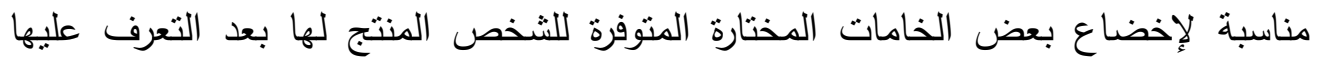

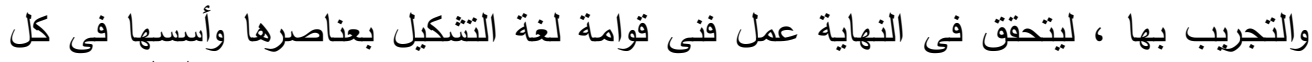

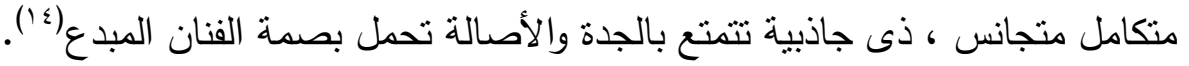

الدراسات المرتبطة:-

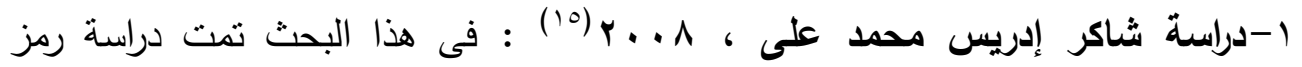
العروسة عبر التراث الإنسانى يؤكد على استمرارية بعض الرئه الرموز ودلالاتها المختلفة

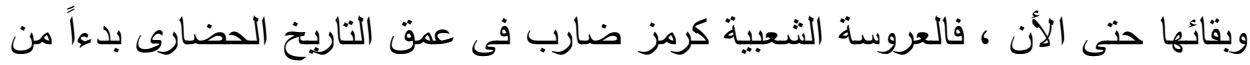

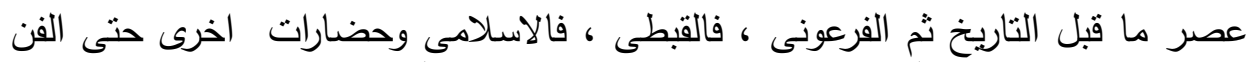

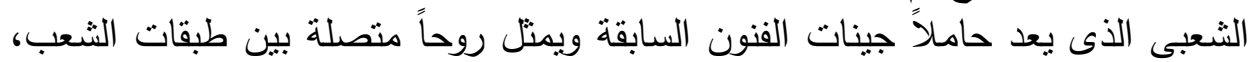

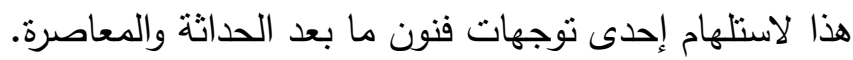

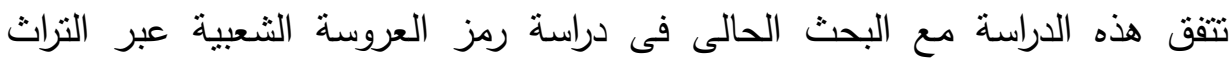

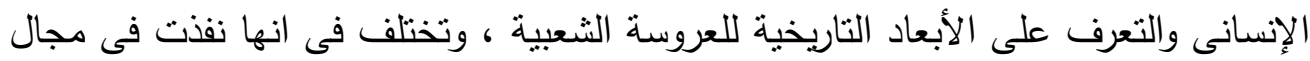
التصوير بينما البحث الحالى سوف يتم تطبيقة فى مجال الإلى الاثتغال الفنية.

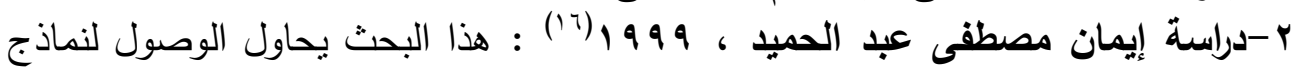

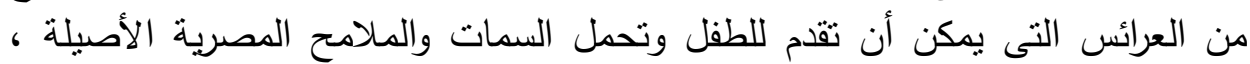

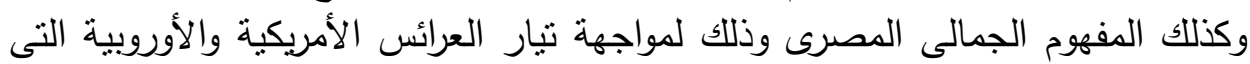

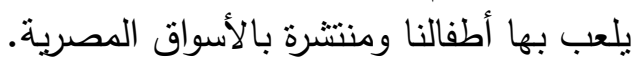

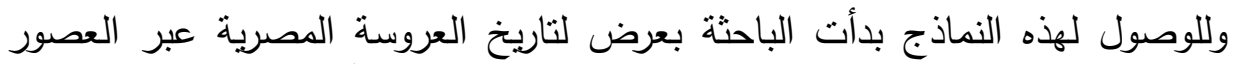

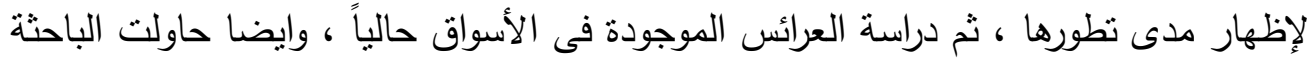

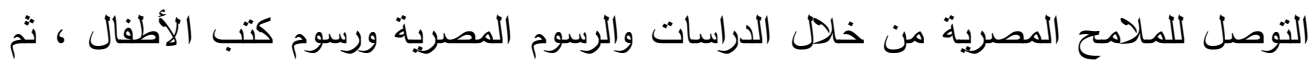

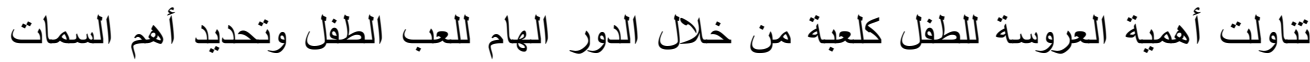
الأساسية للعروسة التى تقدم له له.

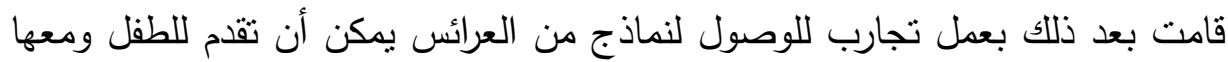

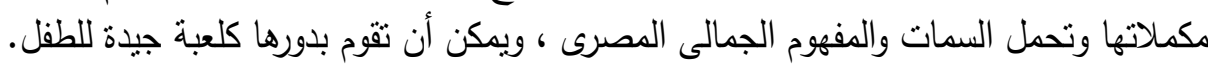

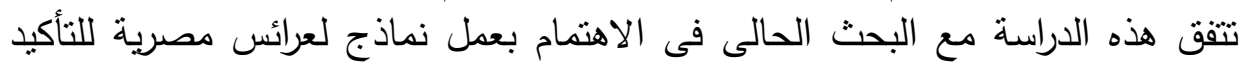

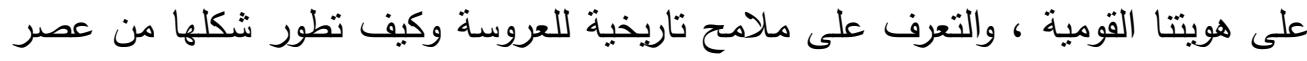

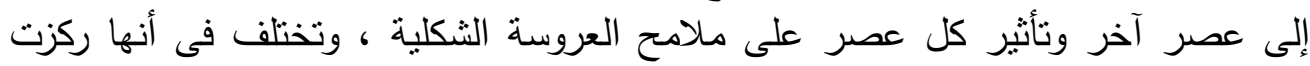

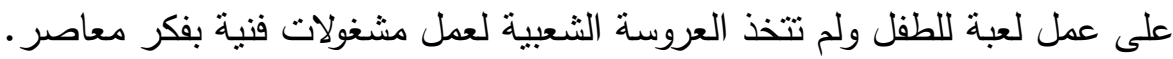

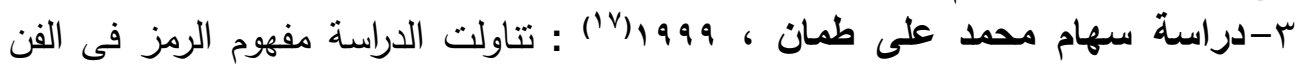

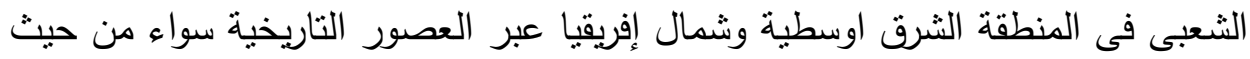


الثكل والمضمون والمحتوى الحضارى له ، وايضا تتبعت الجذور التاريخية للأشكال

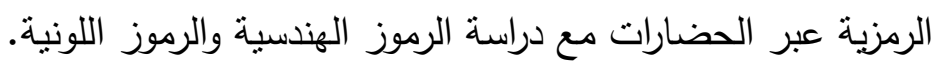

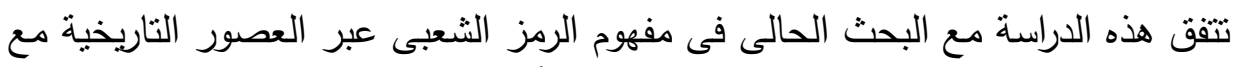

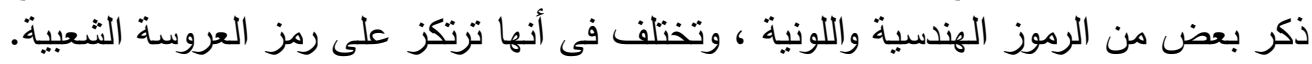

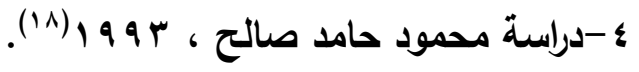

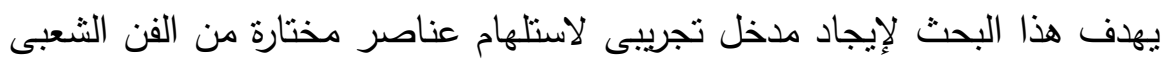

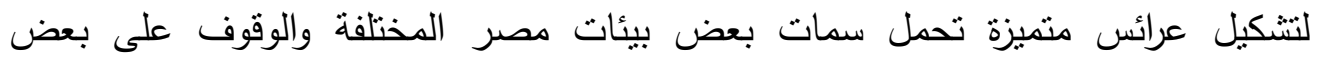
الأساليب التقنية والفنية فى مجال تشكيل العروسة الثتعبية بصياغات مبتكرة وتتاولها بأساليب جديدة.

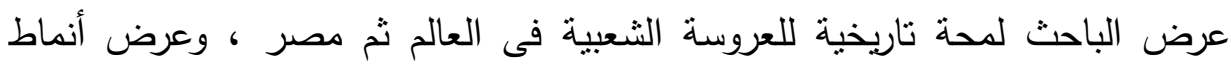

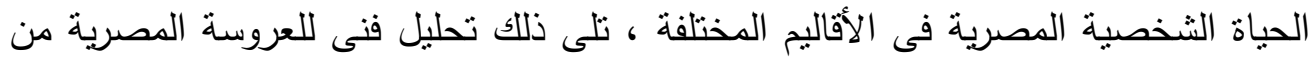

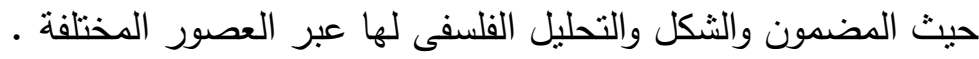

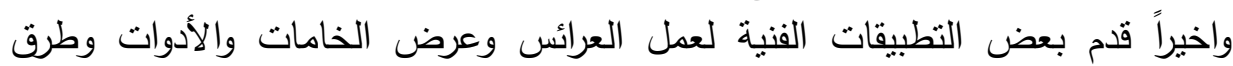
التتكيل ووصف التطبيقات. تتفق هذه الدراسة مع البحث الحالى فى ممارسة التجريب في الخامات المختلفة لاستلهام

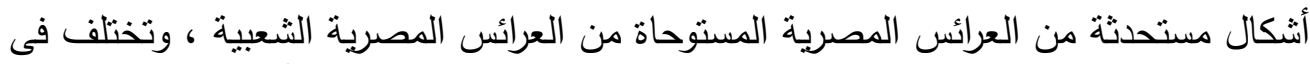

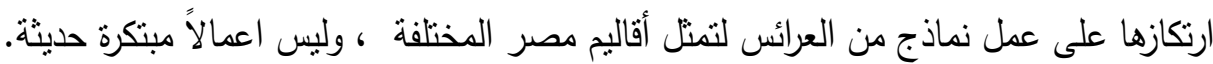

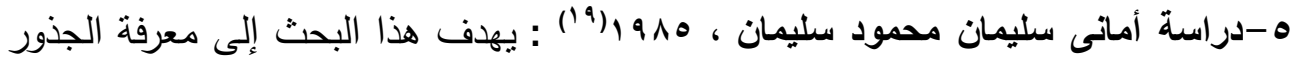

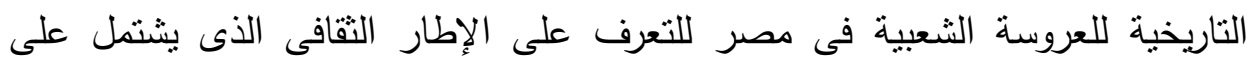

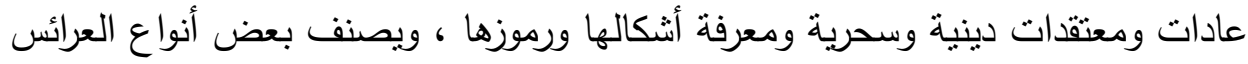

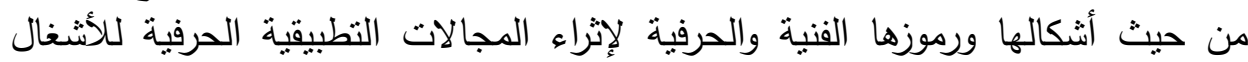

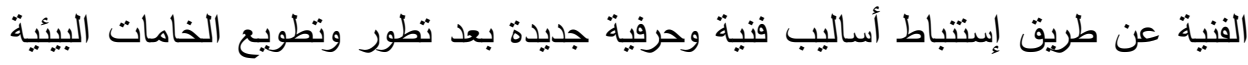

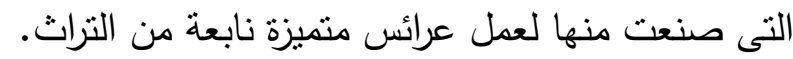

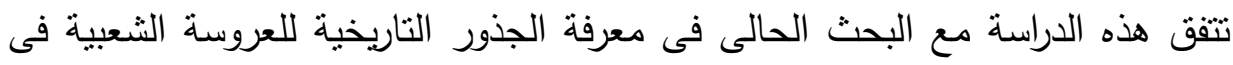

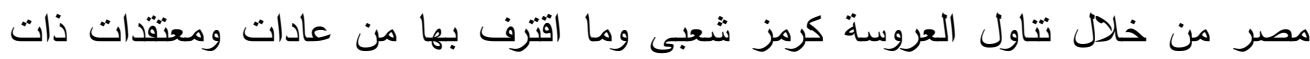

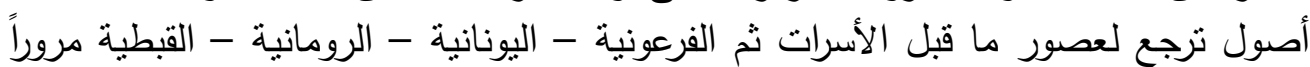

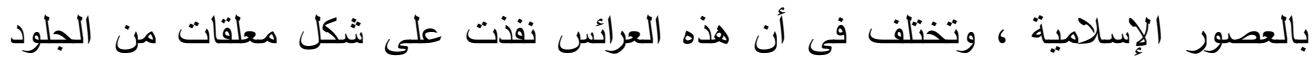
والخامات المختلفة ولم ترتكز على عمل عرائس بشكل ثنائى أو ثلاثى الأبعاد. 


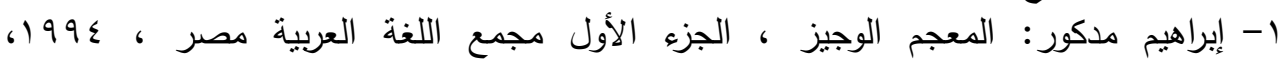

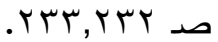
r- ارنست كاسبر : فلسفة الحضارة الإسلامية ترجمة إحسان عباس ، دار الأندلس.

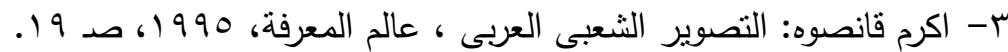

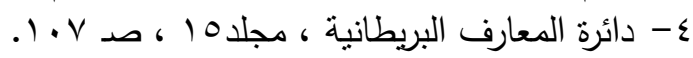

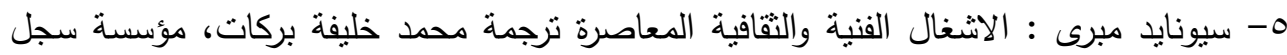

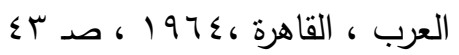

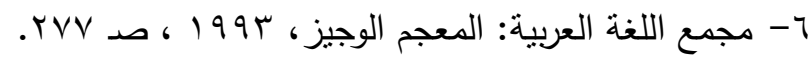

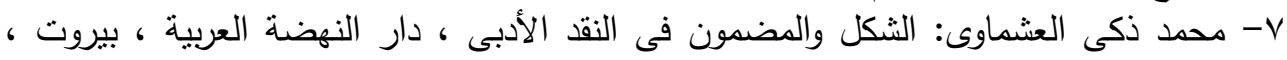

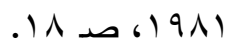

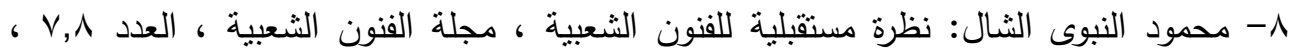

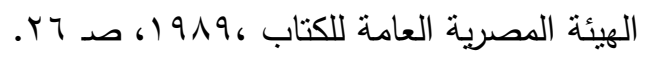

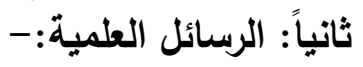

9- أمانى سليمان: العروسة الثعبية فى مصر ومدى الإفادة منها فى المجالات الحرفية المرية المرتبطة

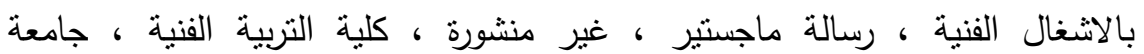

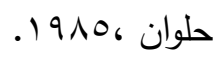

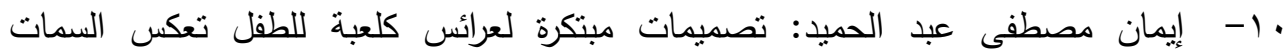

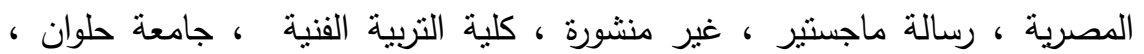
.1999

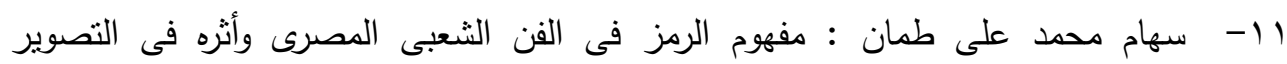

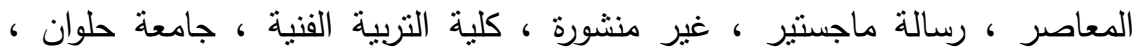

.1999

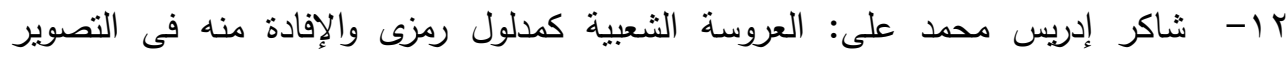

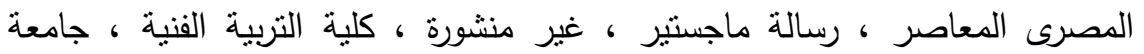

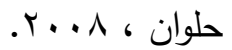

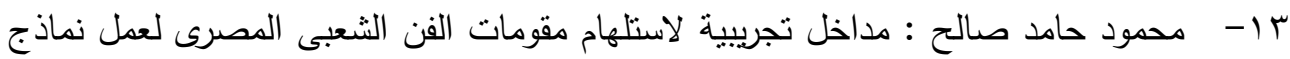

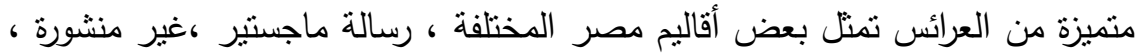

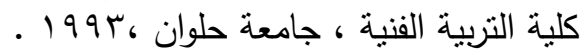

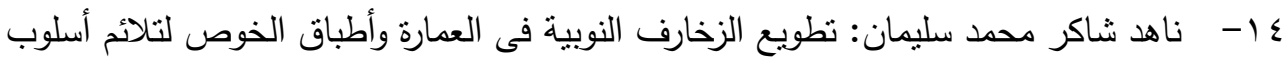

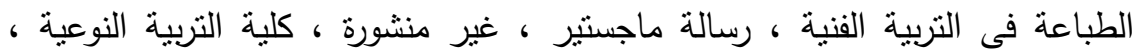

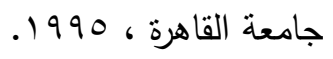

15- Antonia Froser, Dolls, London, 1967, p 9-10 . ثالثا: المراجع الأجنية:--

16- The Encyclopedia Americana, 1983, p 255.

17- Encyclopedia Britannica, 1965 , p 557 . 
1 - محمود النبوى الثال: نظرة مستقبلية للفنون الثعبية ، مجلة الفنون الثعبية ، العدد V,A ، القيئة المصرية

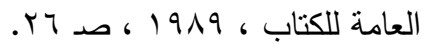

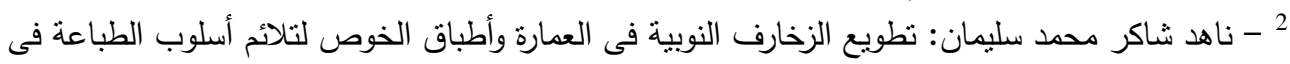

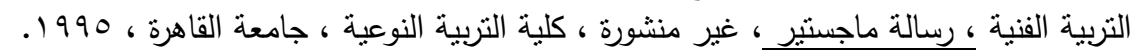

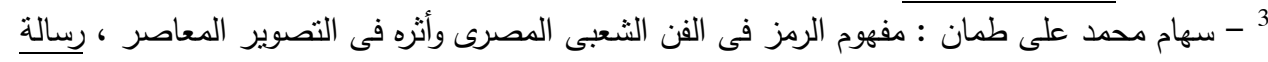

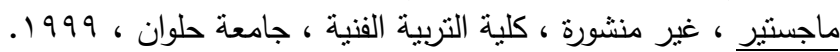

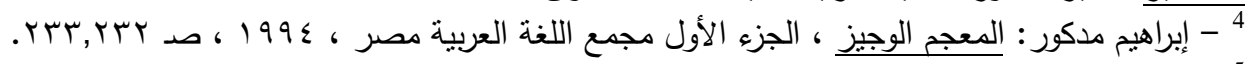

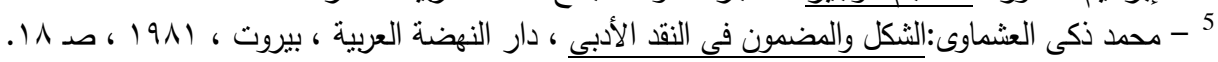

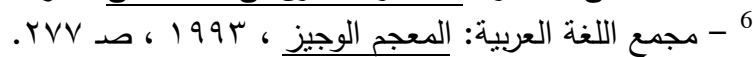
7

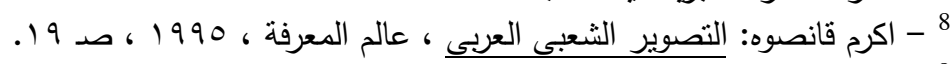
9 Antonia Froser , Dolls , London , 1967 , p 9-10. - 10 The Encyclopedia Americana , 1983 , p 25 - ${ }^{11}$ Encyclopedia Britannica , 1965 , p 557 - ${ }^{12}$ 13 - سيونايد مبرى : الاشغال الفنية والثقافية المعاصرة ترجمة محمد خليفة بركات ، مؤسسة سجل العرب ،

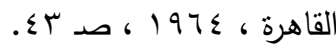

14 - عواطف فتح الله المرصفى: مشغولات الكسوة الشريفة كمصدر لأبتكار اشغال فنية حديثة ، رسالة

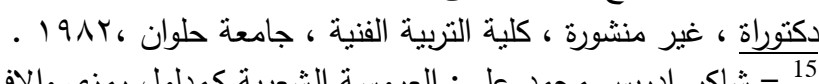

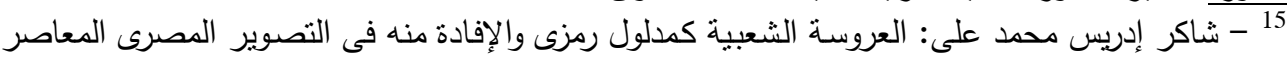

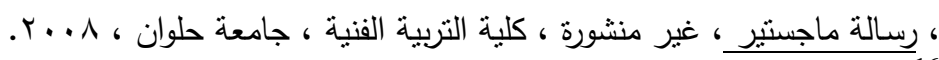

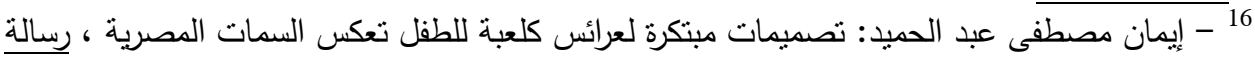

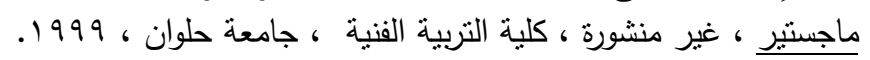

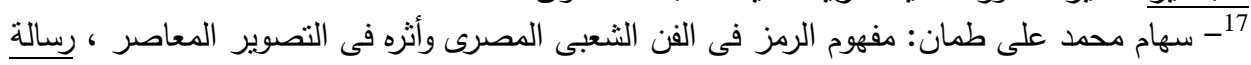

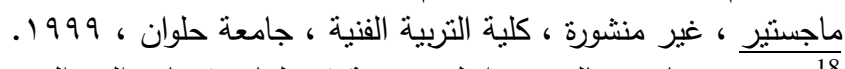

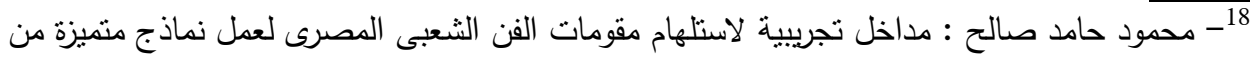

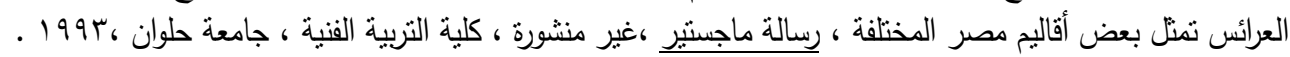

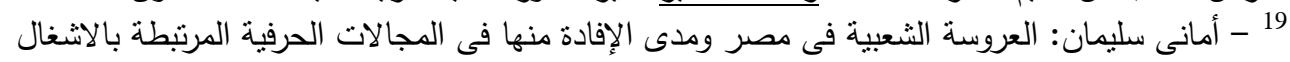

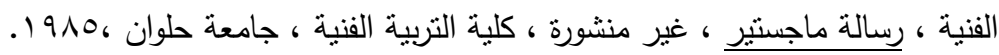

